\title{
Splenic Vein
}

National Cancer Institute

\section{Source}

National Cancer Institute. Splenic Vein. NCI Thesaurus. Code C33608.

A vein arising from the splenic trabecular vein in the hilum of the spleen that drains into

the portal vein. 